\title{
Memories of David Denison
}

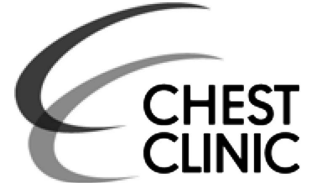
I came up to look around and be interviewed for a job which (rightly) I did not get, and first met David Denison, the professor and head of department. First impressions (subsequently confirmed and reconfirmed) were of a man with an incredibly sharp and original mind, lively in debate and with a great sense of fun, but who was also totally devoid of any pomposity or 'side', to use an old-fashioned phrase. We shared a love for many things, including Jaroslav Hasek's immortal creation, the Good Soldier Schwek (who subsequently appeared on my slides for my first ever BTS presentation, typically drawn by Davidnothing was too much trouble if it tickled his fancy!). David clearly hugely enjoyed life, and enjoyed finding things out. Physiology was obviously an endless fascination to him, and these were the heydays of physiology. Incredibly now, the consolation prize for another unsuccessful candidate at the interview was a research job in a wet lab. I left the interview determined to make it back again.

During a subsequent registrar job, I did a physiology project in the department (which became the Schwek presentation, and a Clinical Science paper) and, subsequently, had a call from David offering me a research fellowship. I accepted with alacrity, and stayed for more than 4 years, obtaining an MD and having

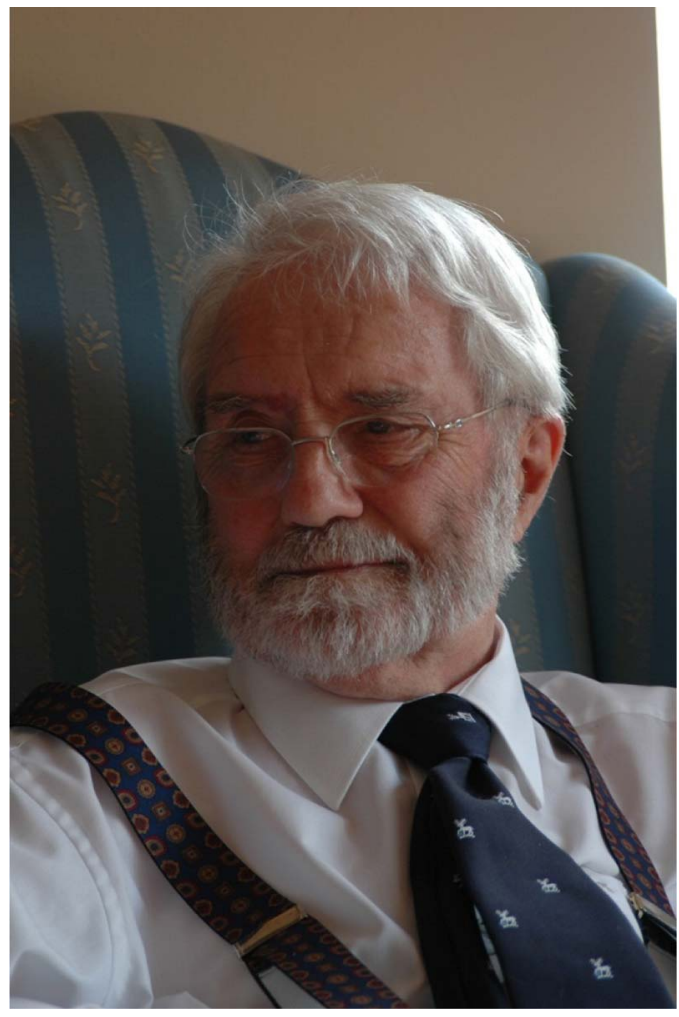

Professor David Denison. 7 March 1933-8 February 2014 my career launched into a new direction, paediatrics, largely by Elliott Shinebourne. I met many fellows there who went on to great things-the current BTS president and the current Respiratory Tsar, to name but two. They were great years.

David inspired huge affection in most of those who worked for him, including me. He could be frustrating-he clearly did not realise, or chose not to realise, how frustrating it was when a much wanted meeting with him was cancelled. Perhaps it has to be said that his approach to the problem of being treble booked and letting someone down in consequence was to refuse to see that there was a problem. When meetings took place, and his sharp mind was brought to bear on the data, they were superb. He was an original, and a nimble-footed thinker; he would have been a supreme barrister, a court-room brawler rather than having the laser-guided strike of a Sir Sydney Kentridge. The grand rounds saw him at his best, frequently baffling his audience with his insights, and even more when his love of debates took him on flights of fantasy which everyone knew just could not be right, but which took his highly intelligent audience days to unpick and realise how comprehensively they had been led by the nose. The professor was the legendary Margaret Turner-Warwick-she obviously had a most motherly affection for him, but with the air of a mother whose chick was something of a maverick, wild child-enjoyment tinged with apprehension as to what might happen next. Had she known some of what went on in terms of physiological experiments on himself and his fellows (in equal measure) she would have been more than just apprehensive! By an entertaining twist of fate, he, by today's standards the most unethical of experimenters (on himself first and foremost) became chairman of the hospital ethics committee-the most egregious poacher turning gamekeeper. Of course he took his chairman's role very seriouslyrightly, investigators were held to the highest standards, but he was ever ready to help in particular the junior investigator. As a clinical scientist David was great. Ideas flowed from him in a great cascade-respiratory mass spectrometry to monitor children with cardiac disease, the Argon Freon measurements of pulmonary blood flow and bronchoscopic assessment of regional lung function in bullous emphysema, stripy lights to measure lung function, especially in spinal injuries, X-ray digitisation to measure split lung function, the use of CT quantitation-these are only some of his achievements in those heady days. He was probably the most original thinker even in the galaxy of talent of the chest department at the Brompton hospital. Each of these techniques indicated David's strengths and weaknesses. Strengths were a unique ability to generate ideas and solve problems in a really innovative way, to put new tools in the hands of clinicians. He generated a truly stimulating atmosphere in the department. However, the weakness was that once he had brought his idea to fruition, and built the kit, he would lose interest at the Heath-Robinson stage. This was, in large measure, because the next instalment of his veritable tsunami of ideas had surfaced. Sadly, he neither wanted to make his new techniques really accessible in a form which a clinician could use in a practical setting, nor allow anyone else to take it forward; indeed, he resented any attempt to take over and move forward any of his ideas. Thus all these great ideas, the source of papers and doctoral theses, never really made the impact that they might have done. Perhaps he should have been a gentleman amateur scientist of the 18th or 19th century; one could easily imagine him debating the equine blood pressure with the Rev Stephen Hales. Ultimately, he tried to solve the problem of artificial blood; rather like Mr Toad, he threw everything into this new idea, throwing everything else overboard, ultimately to no 
avail. Even David could not succeed where the NHLBI and all the US military millions had failed.

The weekly physiology seminars over which he presided with Gordon Cumming had something of the dark inevitability of a Greek tragedy. He was at his most intellectual acute-and in that (as in any debate about data) there was no mercy shown. The hapless speaker would turn up with a huge carousel of slides, but never get beyond slide three, as every statement was instantly challenged and debated at length. The fellows sat at the back, marvelling at the intellectual pyrotechnics, while pitying the wretched victim whose lack of precision, clarity or thought was being exposed, never vindictively, but only to ensure intellectual accuracy. The really robust speaker might come back for a second go, with the same carousel—but slide six would still be as far as they got. When the hour was up, the audience abandoned the speaker for the grand round, and that was that; only the fellow who had invited the speaker remained behind to try to administer consolation and Prozac to a once bright-eyed and hopeful person.

His expertise ran far beyond hospital physiology. He had a vast and entertaining knowledge of comparative physiology. Why do diving mammals not get the bends-answer, they have cartilage reinforced airways all the way distally and no residual volume. How does a pregnant seal swim 40 miles under the polar icecap, find a hole to surface, and give birth to a sopping wet pup in a howling arctic gale, and mother and baby survive? He was a fund of knowledge on diving and aviation physiology - a true Renaissance physiologist.

He loved children, and in many ways was a great overgrown child. My wife took our oldest boy to a Christmas lecture delivered by David-the subject being how to make a submarine out of a cardboard box. An audience of small children and their parents were enthralled. I rather think, given the choice, David would have preferred the cardboard box version to the real thing. Any visiting child (as mine frequently did) could always rely on David to entertain them, no matter how busy he was.

Among his many great strengths was that he was intensely loyal. Do the job for David, and he was your supporter for life. Woe betide anyone who upset David's fellows; I well remember a grand round when, having rightly or wrongly imagined a consultant had mistreated one of his team, he went in spoiling for a fight, and as soon as the culprit opened his mouth, his verbal fists flew and his victim was destroyed in a very public place. $\mathrm{He}$ also inspired intense affection and loyalty; few if any of his fellows left without cherishing a lifelong affection for him, and would have been ever ready to come back to help if needed. Perhaps the opposite side was, sadly, he could take an (often irrational) dislike to a fellow-and very often, from there, there was no way back.
Politically, he was totally naive, and this was ultimately to be his undoing. Routine was anathema to him; he would far rather be on the case of new ideas. So with Derek Cramer he set up the clinical laboratory, and David worked out innovative ways of displaying the results, but he then withdrew, leaving Derek to run the show (which of course he did, supremely capably). As far as the clinical service went, his research fellows reported the test results, and long months could go by without his presence or absence impacting on the patients. Of course he had areas of expertise that were unique, such as aviation and diving medicine, and it could truly be argued that for him to waste time on the $\mathrm{FEV}_{1} / \mathrm{FVC}$ ratio would be a Derby winner pulling a milkcart. But when the chill wind of financial cuts came, it was inevitable that it blew on him first of all, and he was deposed from his beloved physiology department.

At a personal level, he was a complex mix. He combined extreme generosity with total financial penury. He always had a soft spot for women, and would be particularly generous to them. He could be uncharitable, and perhaps some of those he identified as fools maybe had more to offer than he acknowledged, and he should have been suffered more gladly. He was always big-hearted, and warm-hearted; he may have had his follies (who does not?) but they were the follies of a big and generous man. There was no trace of pettiness or meanness about David.

So overall? Working with David was not always a bed of roses, but I stayed more than 4 years and great times were the majority. Taken together, the fellowship was one of the best and most stimulating times of my career, despite the rollercoaster ride. I, as many others, owe him a huge debt. He despised petty orthodoxy. He was truly a once-in-a-lifetime man. That he was great was undeniable; that his greatness would not flourish in the crabbed confines of today's NHS or academia is depressingly certain.

\section{Andrew Bush}

Correspondence to Prof Andrew Bush, Imperial College and Royal Brompton Hospital, Sydney Street, London SW3 6NP, UK; a.bush@imperial.ac.uk

\section{Competing interests None.}

Provenance and peer review Not commissioned; internally peer reviewed.

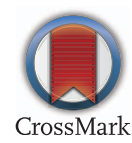

To cite Bush A. Thorax 2014;69:591-592.

Published Online First 26 March 2014

Thorax 2014;69:591-592. doi:10.1136/thoraxjnl-2014-205373 